\title{
CONSTRUCT TEACHING MATERIALS FROM HL7/CDA ELECTRONIC PATIENT RECORDS ACCORDING TO SCORM STANDARD FOR MEDICAL EDUCATION
}

\author{
YAW-JEN LiN ${ }^{1}$, JAMES WANG $^{2}$, NiCK ShU ${ }^{1}$, FoK-Ching ChANG ${ }^{2}$ \\ ${ }^{1}$ Dept. of Information Management, Yuda University, Miaoli County \\ ${ }^{2}$ Dept. of Electrical Engineering, National Taiwan University \\ Taiwan
}

\begin{abstract}
The rise of Web technology leads to the convenience of global information exchanges. Furthermore, E-Learning takes full advantage of cross area characteristic of the web, enabling online learning, at any time, at any place. Thus, SCORM (Sharable Content Object Reference Model) was result of such a trend. This study is based on CDA example teaching materials provided by international HL7 organization, attempting to combine with SCORM standard, constructing a teaching material, which can be provided to hospital doctors, interns, or students while learning HL7/CDA. The teaching materials are based on SCORM standard. Besides in class use, the teaching materials can be shared and used on any SCORM-compliant LMS (Learning Management Server) platform. In addition, the user can edit data of selected cases come from HIS (Hospital Information System) directly on the teaching materials web pages, exporting into HL7/CDA compliant clinical documents, saving extra programming time to achieve inter-hospitals information sharing.
\end{abstract}

Biomed Eng Appl Basis Comm, 2004 (August); 16: 190-198.

Keywords: E-Learning, SCORM, HL7, CDA, LMS

\section{FOREWORD}

Entering 21 st century, global competition is getting intensified. Enhancing the nation's competitiveness relies on investing on citizen education and boosting their skill levels. In conjunction with the vigorous development of computer and networking technology, we have gradually entering web learning from book learning. E-learning subject gains world most attention [1].

Among e-learning standards, healthcare information e-learning course is one of the major

Received: Feb 17, 2004; Accepted: July 5, 2004

Correspondence: Yaw-Jen Lin, Professor

Dept. of Information Management, Yuda University, Miaoli County, Taiwan

E-mail: lyr@msl.ydu.edu.tw international development efforts. In healthcare information standards relating to patient record, HL7 ( Health Level Seven ) is well known among healthcare information industry. It is also being accepted by many countries as the standard to exchange hospital healthcare information. HL7, through defining information exchange standard among healthcare applications, simplifies the complexity of the system integration among diverse applications, and achieves the principle of information sharing. A CDA (Clinical Document Architecture) document can provide standardized clinical document exchange among hospitals. Using CDA document, one can transmit HL7 healthcare information.

In e-learning standards, leaded and promoted by U.S. Defense Department and the White House ADL (Advanced Distributed Learning) initiative, sharable and component based SCORM is the most acceptable e-learning standard [5]. Its goals are to achieve 
Reusability, Accessibility, Durability, Interoperability, Adaptability, Affordability, and Manageability [2]. At present time, SCORM is in version 1.2. It details elearning metadata standard. Coupled with widely accepted international healthcare information $\mathrm{HL} 7$ standard, we are going to combine SCORM standard and examples on the CDA specification, producing a HL7/CDA example teaching materials. It shall become a web based e-learning teaching example for medical college staff and hospital interns.

This study conforms to HL7 version 2.4 and CDA 2.0 standard proposed by international HL7 organization, attempting to combine them with SCORM 1.2 standard, in order to achieve e-learning goal, i.e. construct a HL7/CDA example teaching matcrials to promote CDA teaching resources Reusability, Accessibility, Durability, Interoperability, Adaptability, Affordability, Manageability, etc.

\section{LITERATURE DISCUSSION}

This paper referenced two standards: healthcare information standard HL7 and e-learning standard SCORM. HL7 standard has 3 sub-standards. They are Healthcare Information HL7 (Health Level Seven), CDA (Clinical Document Architecture) and CDA RIM (Reference Information Model). Currently, three standards are not completely integrated. Wait until HL7 version 3.0, there will be CDA standard incorporated into $\mathrm{HL} 7$ messages. At present time, it is still in voting stage, not yet officially published. This paper focused on CDA 2.0 clinical document architecture message. It does not include HL7 messages. As for e-learning, it is based on SCORM (Sharable Content Object Reference Model), leaded by international ADL organization. Among SCORM standards, this paper focused on the discussion of Content Aggregation Model. E-learning Run Time Environment standard is not discussed in this paper. Standard contents are discussed below :

\subsection{CDA (Clinical Document Architecture)}

HL7 CDA is designed to accomplish document exchange. Its goals and design principal are to provide a reference standard to store patient medical record and exchange the same information among institutions. It is structure specific and semantics specific document module. Clinical documents include observation, service, etc. It also has the following characteristic:

1. Persistence: A CDA document continues to exist in an unaltered state, for a time period defined by local and regulatory requirements.

2. Stewardship: A CDA document is maintained by a person or organization entrusted with its care.

3. Potential for authentication: A CDA document is an assemblage of information that is intended to be legally authenticated.

4. Integrity: CDA is suitable for all types of healthcare documents, not limited to local healthcare documents.

5. Human readability: A CDA document is human readable.

6. Interoperability: CDA definition is broad, includes text, images, and other media contents.

CDA structure mainly consists of "CDA Level One" as root structure to cover the complete document. "CDA Level One" specifies complete document structure and as such can stand alone, prior to the completion of the specification of the complete architecture.

Under "CDA Level One" structure, one can inherit "CDA Level Two" and "CDA Level Three" to extend the description of the document content. CDA document content is comprised of $\langle$ Header $>$ and $<$ Body $>$. < Header> establishes the document type, provides information on authentication, the encounter, the patient, the provider, etc.; <Body>, containing the clinical report. ( $<$ Body $>$ in CDA Level One is referred as "CDA Level One Body"), is comprised of nested containers, which include plain text, links and multimedia. Both $<$ Header $>$ and $<$ Body $>$ use RIM architecture to define document structure type. (reference http://www.adlnet.org/screens/shares/dsp displayfile.cfm?fileid=477/SCORM_1[1].2_CAM .PDF P.36 Figure).

\subsection{SCORM (Sharable Content Object Reference Model)}

This paper referenced SCORM version 1.2. Based on course requirements, one cuts the teaching materials into SCO (Sharable Content Object) or Asset file. Asset is the smallest element in the material. Examples such as an image, a video file, sound file, can be viewed as Asset; and SCO is the smallest teaching unit. A complete course structure is aggregated from SCOs. See Figure 2.2.1.

In teaching material definition, SCORM describes a teaching matcrial with 9 categories. In the table below, grey part stands for each category. It defines 83 Metadata Elements. However, not every element is required. There are 22 required elements, which appear in the Metadata file of every teaching material. Summarized below : 
Table 2.2.1. SCORM Metadata Element Table

\begin{tabular}{|c|c|c|c|}
\hline Name & Description & $\mathrm{SCO}$ & Asset \\
\hline 1.0 general & $\begin{array}{l}\text { Describe general overall information of } \\
\text { learning resources. }\end{array}$ & required & required \\
\hline 1.2 title & Title of leaming resource. & required & required \\
\hline 1.3 catalogentry & $\begin{array}{l}\text { Apply an existing classification and } \\
\text { describe how to define learning resources } \\
\text { with this classification. }\end{array}$ & required & optional \\
\hline 1.3.1 catalog & Name of the classification. & required & optional \\
\hline 1.3.2 entry & $\begin{array}{l}\text { Actual value of learning resources under } \\
\text { this classification. }\end{array}$ & required & optional \\
\hline 1.5 description & $\begin{array}{l}\text { Text to describe learning resources under } \\
\text { notation. }\end{array}$ & required & required \\
\hline 1.6 keyword & $\begin{array}{l}\text { Key character or key words to describe } \\
\text { learning resources. }\end{array}$ & required & optional \\
\hline 2.0 lifecycle & $\begin{array}{l}\text { Describe the historic background or the } \\
\text { present condition of the learning resources, } \\
\text { and the person impacting it, during the } \\
\text { evolution process of the leaming resources. }\end{array}$ & required & optional \\
\hline 2.1 version & The edited version of the learning resource. & required & optional \\
\hline 2.2 status & $\begin{array}{l}\text { The condition or status of the learning } \\
\text { resource. Limited vocabularies are Draft, } \\
\text { Final Revised, or Unavailable. }\end{array}$ & required & optional \\
\hline 3.0 metametadata & $\begin{array}{l}\text { Special information with regard to metadata } \\
\text { itself. }\end{array}$ & required & required \\
\hline $\begin{array}{l}3.4 \\
\text { metadataschema }\end{array}$ & $\begin{array}{l}\text { Name and version to comply with metadata } \\
\text { specification. }\end{array}$ & required & required \\
\hline 4.0 technical & $\begin{array}{l}\text { Describe the technical requirement and } \\
\text { characteristic of the learning resource. }\end{array}$ & required & required \\
\hline 4.1 format & Technical information format of the & required & required \\
\hline
\end{tabular}




\begin{tabular}{|c|c|c|c|}
\hline & learning resource. & & \\
\hline 4.3 location & $\begin{array}{l}\text { Explain string for storing the learning } \\
\text { resource, such as URL or URI. }\end{array}$ & required & required \\
\hline 6.0 rights & $\begin{array}{l}\text { Describe the intellectual property of the } \\
\text { learning resources and the conditions of the } \\
\text { usability of the learning resource. }\end{array}$ & required & requirea \\
\hline 6.1 cost & $\begin{array}{l}\text { Explain whether having to pay for the } \\
\text { learning resource. Limited vocabularies } \\
\text { are Yes or No. }\end{array}$ & required & required \\
\hline $\begin{array}{l}6.2 \\
\text { copyrightandoth } \\
\text { restrictions }\end{array}$ & $\begin{array}{l}\text { Is there any copyright or other limitation } \\
\text { when using this learning resource? } \\
\text { Limited vocabularies are Yes or No. }\end{array}$ & required & required \\
\hline 9.0 classification & $\begin{array}{l}\text { Explain the location of the learning } \\
\text { resources in a popular classification system. }\end{array}$ & required & optional \\
\hline 9.1 purpose & $\begin{array}{l}\text { The classification purpose for the learning } \\
\text { resource. Limited vocabularies are } \\
\text { Discipline, Idea, Prerequisite, Educational } \\
\text { Objective, Accessibility Restrictions, } \\
\text { Educational Level, Skill Level or Security } \\
\text { Level. }\end{array}$ & required & optional \\
\hline 9.3 description & $\begin{array}{l}\text { Describe the relationship between the } \\
\text { learning resource and the its classification } \\
\text { purpose. }\end{array}$ & required & optional \\
\hline 9.4 keyword & $\begin{array}{l}\text { The key character or the key word to } \\
\text { describe the learning resource and its } \\
\text { classification purpose. }\end{array}$ & required & optional \\
\hline
\end{tabular}

\section{STUDY MOTIVE AND PURPOSE}

The goal of Healthcare information standard HL7 defined by the international HL 7 committee is to facilitate information communication and exchange among hospitals. And CDA is used in clinical healthcare as healthcare information exchange document for describing information [4]. For nonhealthcare information person, it is not only difficult to learn CDA document architecture, but also painful to implement actual patient record into CDA. Thus, this study is coming from learner's point of view, implement CDA example document structure provided 


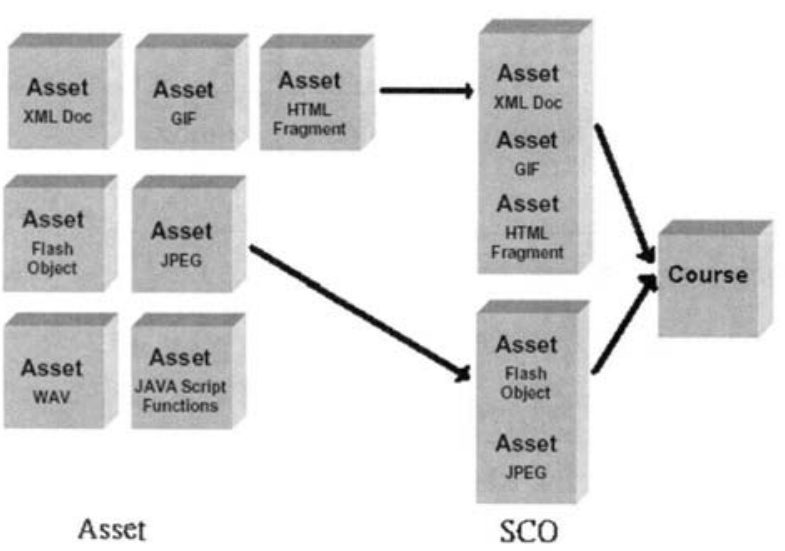

Fig 2.2.1. SCORM course structure map

by $\mathrm{HL} 7$ organization into SCORM standard, resulting in e-learning teaching materials. It is also constructed on SCORM-compliant LMS platform applications. Later we are going to introduce the principle of implementation and the implementation tools. We use an open-source e-learning platform for university hospital LMS (Learning Management System) as the teaching material implementation, and proceed to actual construction of the Structure Theory assisted learning teaching materials.

As stated earlier, this study generates SCORMcompliant sharable teaching materials based on HL7/CDA example documents. The teaching materials provide the following teaching functions:

1. Provide teaching material tools for the CDA case study.

2. Assist the hospital to implement clinical document in CDA formats as reference base.

3. Make use of the reorganize able characteristic of the teaching materials, the users (teachers, physicians, or students) can freely choose, reorganize or edit content on CDA examples, as teaching materials for the classes or reference bases for the patient record implementation of the CDA document.

4. The users can directly edit the content of a CDA document, export into a standard CDA document. Without reprogramming and understanding of CDA document architecture, the users can compile a CDA document easily.

\section{STUDY METHODS}

This study is mainly divided into four stages to be carried out. And the runtime platform is Microsoft Windows XP operating system. The development tools are Microsoft Office InfoPath 2003 and XML writer 2.2. System is Intel CPU $1.7 \mathrm{G}, 256 \mathrm{M}$ RAM , $40 \mathrm{G}$ hard disk.

First of all, in the first stage experiment, we conducted requirement discussion. In the second stage, we began to gather related literatures to study. In the third stage, we actually compiled the teaching materials. Lastly, we implemented the teaching materials on LMS platform application. Explains as follows:

1. Research Requirement Stage: Due to the fact that the teaching materials shall provide convenient learning tools to the end users, in the initial stage, we visit and consult veterans in this domain to avoid producing teaching materials against the teachers' use habits.

2. Literatures collection stage: This study references the examples on the ADL website. It also takes CDA examples from HL7 organization [6] as the teaching material examples. And later we collects SCORM, HL7/CDA related literatures one after another to study.

3. Teaching Materials Development Stage: The teaching material development and producing stage is mainly responsible for implementing CDA example documents into SCROMcompliant format. The implementation focused on the cutting of CDA document and the compiling of SCORM Metadata.

4. Course Implementation on Platform Stage: The finished teaching materials are expected to be implemented on an open-source e-learning platform for university hospital for actual teaching. The platform serves as the platform for "2003 e-learning Country Science and Technology Plan -Development E-Learning Center for Medical and Health Education in University Hospital". This platform complies with SCORM LMS standard and can be used as the platform interface tool for teaching material management and e-learning.

\section{STUDY RESULT}

CDA document is a clear illustration of a hierarchy structure. SCORM standard has three types of content, i.e. Asset, SCO, and CP (Content Packaging). Based on CDA and SCORM structure characteristic, this study implemented HL7/CDA example document into SCROM standard. Its architecture workflow is explained as follows:

1. CDA document analysis

2. SCORM-compliant teaching material cutting format 
3. The Transformation between CDA document and SCORM standard

a. Structure Transformation

b. Element Transformation

c. Tag Correspondence

4. Metadata file to generate teaching material

5. Manifest file to generate organization course structure

6. Embed SCORM defined CDA teaching material in courseware web page

\subsection{CDA Document Analysis}

CDA document includes $<$ head $>$ and $<$ body $>$ two sections. The $<$ head $>$ incorporates provider, institution and instrument, patient information, amended record as main analysis element. Use examples mentioned in the CDA 2.0 specification, which includes $<$ ComponentOF>, <Supervisor>, <Author>, $<$ Custodian $>$ and $<$ Patient $>$ five sections [7]. And $<$ body $>$ uses <section> as element. Every <section> describes a study information. The <section $>$ is sub sectioned to <component> to describe the content of the exam information for every study. Take $<$ Physical Exam section $>$ in the specification as an example, each study is sub sectioned into skin examination, Cardiopulmonary examination, etc. Every study shall have many <component $>$ to describe it, constitutes a clear illustration of hierarchy information (such as Figure 5.1.1).

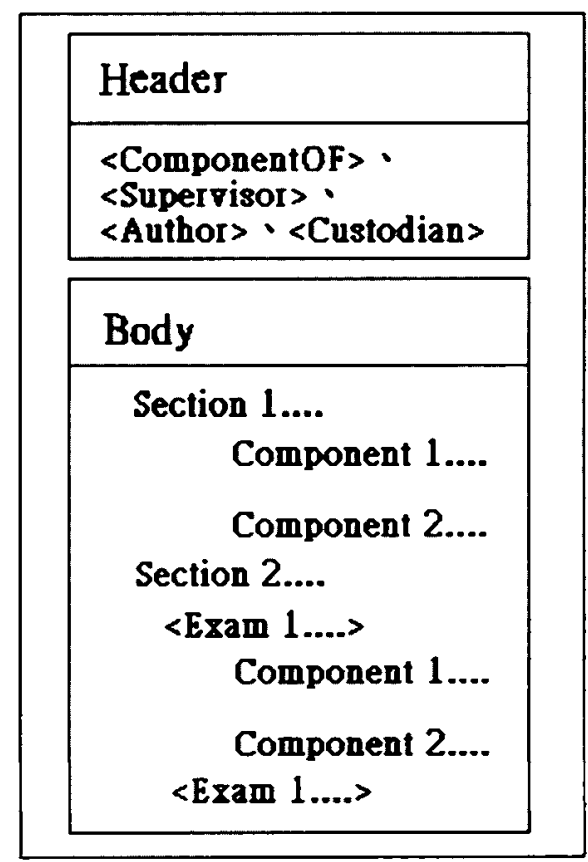

Fig 5.1.1. CDA Hierarch Illustration

\subsection{SCORM-Compliant Teaching Material Cutting Format}

SCORM-compliant course structure is to package together specific Learning Resources according to a course coverage so that LMS can launch this course. SCORM content aggregation model includes Content Model, Metadata, and Content Packaging. Three standards described below:

1. Content Model: Content model includes Asset and Sharable Content Object, SCO. Asset is the smallest element, such as an image, a video file, a text paragraph; For $\mathrm{SCO}$, it is a collection of Assets and a stand alone instructional material.

2. Metadata: Metadata let the learner use "search" tool to look for possible fragmented clues in order to form knowledge necessary to solve the problems at hand. Therefore, all levels of the Jearning element has to be tagged with Metadata. SCORM Metadata standards mostly come from IEEE and IMS standards, which include Asset , SCO, or Aggregations tagged with Metadata.

3. Content Packaging: The purpose of content packaging is to provide a standardized way for packaging. It makes course authoring tool to package a standard course stored in the content repository, which is accessible by different LMS. Simply speaking, content packaging put together related learning resources (SCO and Assets) structural reorganization. Packaged Content is shown in the figure below. (Fig. 5.2.1).

\subsection{Transformation between CDA Document and SCORM Standard}

We use the examples in the CDA specification to implement courseware practice according to SCORM standard. This study first performed structure transformation from CDA document to SCORM course. Next, performed element transformation for SCORM standard, finally performed tag correspondence, as follows:

\subsubsection{Structure transformation}

In this step, we performed initial transformation step by step from HL7/CDA example document to SCORM-compliant course structure. First of all, we cut CDA document structure extensively according to CDA specification. CDA Level One is a ROOT level, which includes $<$ header $>$ and $<$ body $>$ segments. We defined these two segments as MultipleSCOs; Level Two extends Level One, includes exam study information, we defined <Section> in the Level Two as SCORM SCO or MultipleSCO teaching element; Level Three extends Level Two, includes additional 


\section{CDA document structure Course structure}

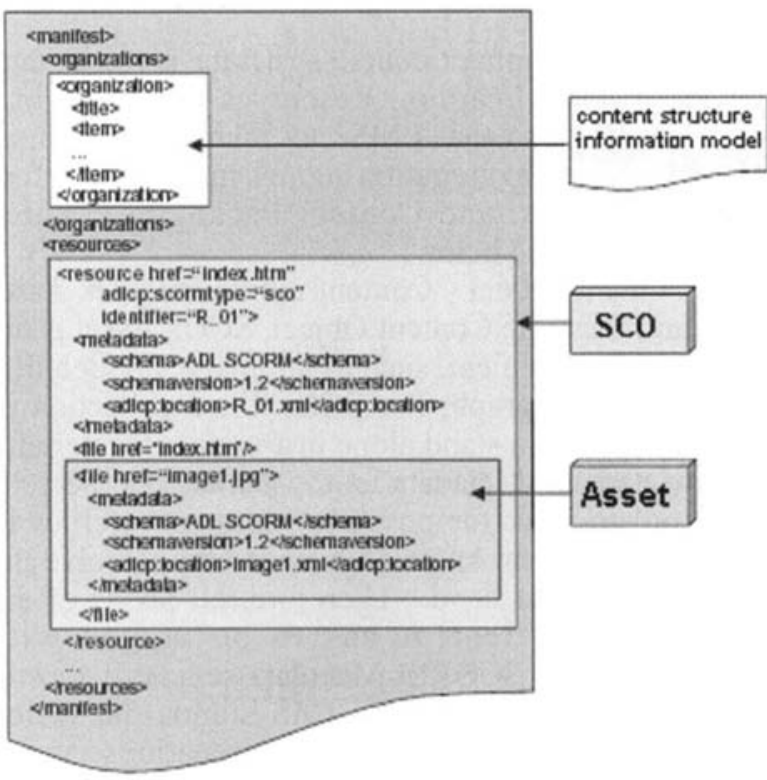

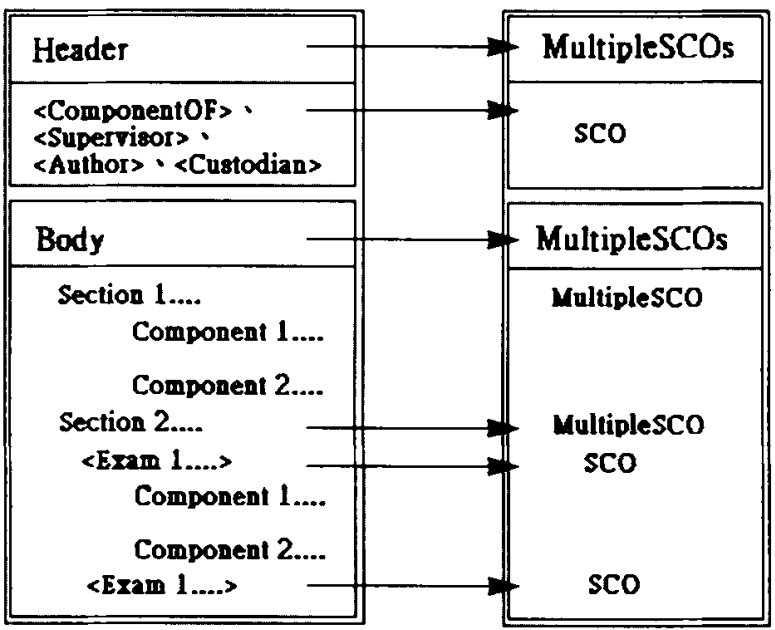

Fig 5.3.1.1 . Structure Transformation Map

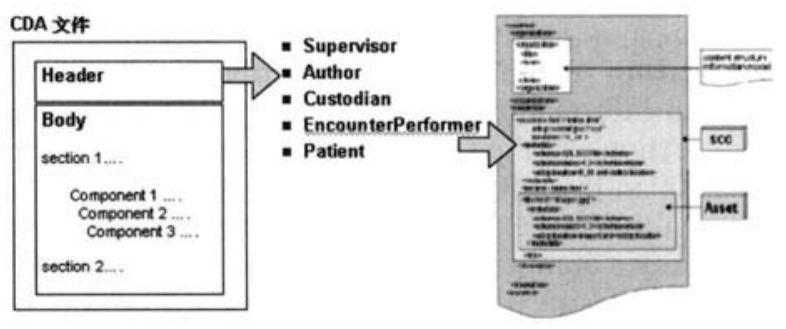

Fig. 5.3.2.1 . CDA_Head Element Transformation Map

\subsubsection{Element transformation}

In the second step, we would choose the most suitable Asset, SCO, or Content Aggregation for course compilation according to the element size. Explains as follows:

CDA_Head section, individual <componentOF>, <supervisor>, <author>, <custodian> and <patient> is cut into SCORM-compliant SCO file (such as Fig. 5.3.2.1).

And Fig. 5.3.2.2 shows the cutting of every Section in CDA Body into MultipleSCO. If DICOM format file or medical signal file is encountered, treat it as Asset file.

\subsubsection{Tag transformation}

In the third step, we analyze CDA tag element and existing SCORM Metadata tag to compare semantics. If the semantics meaning mentioned in the CDA document is the same (or similar) to that of SCORM Metadata tag, then store CDA tag content directly into SCORM Metadata. In other cases, depending on CDA document content, choose important information content and store it in SCORM Metadata "keyword" tag or annotate the special information described in the

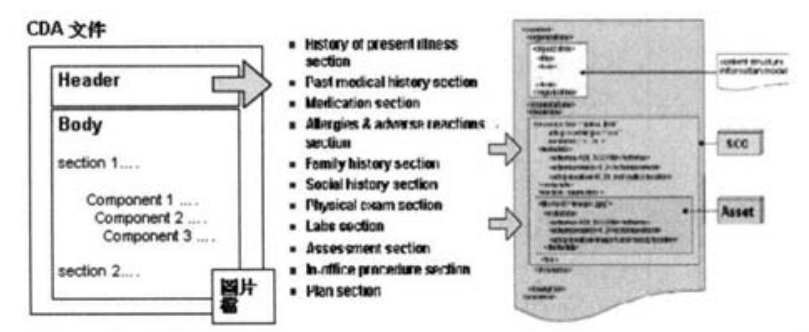

Fig. 5.3.2.2. CDA_Body Element Transformation Map

CDA document with SCORM Metadata <note>. Therefore, increase the readability of Metadata.

\subsection{Course Generation of Metadata File}

In this CDA example course, we define such an example as a "Course", which includes CDA_Header and CDA_Body, two Paragraphs. Element under is Section. Thus, cutting a HL7/CDA document resulted 
in a copy of CDA Content Aggregation course, CDA Header section, which includes one copy of MultipleSCOs and six copies of SCO course files. And CDA_Body section includes one copy MultipleSCOs and eleven copies of MultipleSCOs and four copies of SCO course teaching materials. The material has one teaching material figure file, Asset After completion, the total course includes one copy of CDA Content Aggregation course, two paragraphs of MultipleSCOs, eleven copies of MultipleSCO Paragraphs, four copies of SCO Section and one copy of Asset Material.

To compile course in Metadata file, we use InfoPath 2003 provided in Microsoft Office2003. We developed SMES (SCORM Metadata Edit System), which complies with SCORM data field. Its system devclopment interface is described below: The tree like menu on the right hand side is SCORM Metadata System Design Structure, the user interface on the left hand side is where the data input of Metadata takes place. The required information is noted with "*". When we are compiling Metadata file, we do not have to understand SCORM Metadata specification before being able to directly input course information text into the status input fields. The output then becomes course Metadata XML file.

Take CDA Header <Author> as an example, after we input information into required fields, the rest of the fields can be left blank. The system output complies with SCORM described Metadata XML and is described below (Fig. 5.4.2).

As stated earlier, we need to compile Metadata file respectively for 2 copies of MultipleSCOs, eleven copies of MultipleSCO paragraphs, four copies of SCO paragraphs, one Asset Material. A complete copy of SCORM-compliant CDA course is then finished.

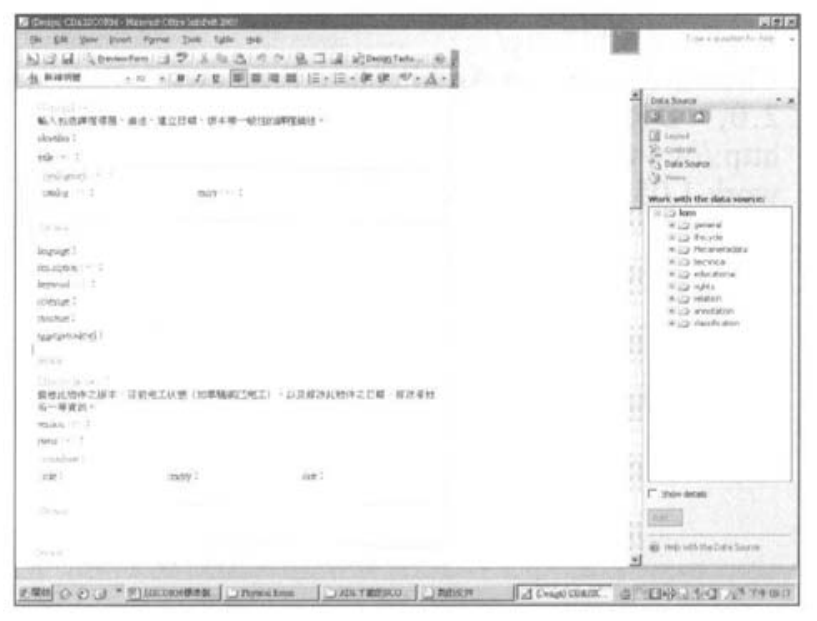

Fig 5.4.1. SCORM Metadata Edit System (SMES)

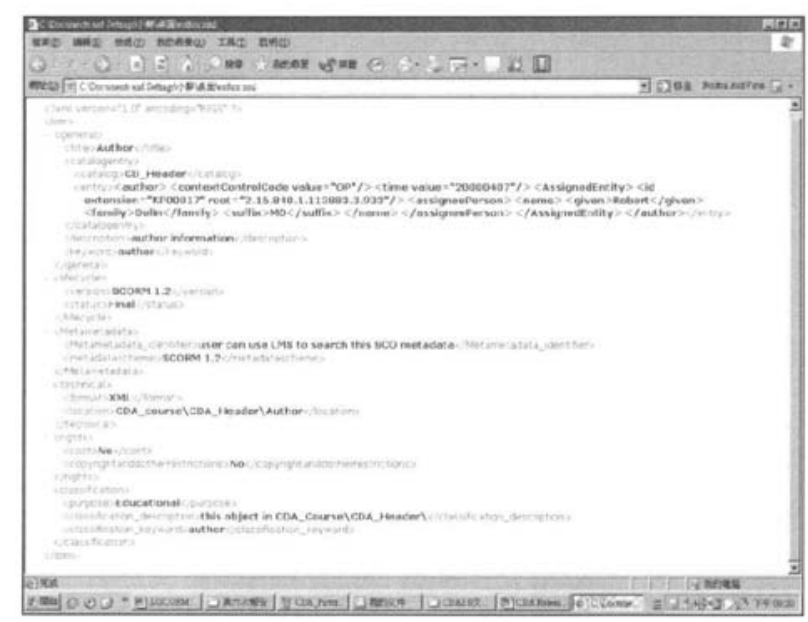

Fig 5.4.2. SCORM Author Metadata

\subsection{Manifest File to Generate Organization Course Structure File}

We follow SCORM standard content packaging to package our course, so that course authoring tools can generate a standardized course stored in the content repository, which is accessible by different LMS. Several important files are described below:

(1) index.html: the main file to access this course.

(2) index.xml: the metadata file to record this course generality.

(3) imsmanifest.xml: this file records a course composition structure, the locations of every learning resource, and other related metadata. This file also records the access sequence of SCO and Assets (Fig. 5.5.1).

\subsection{Embed SCORM Defined CDA Teaching Materials in Courseware Web Page}

For file uploading, this course uses an opensource e-learning platform for university hospital prototype system as course uploading platform. This system complies with SCORM LMS standard and can provide individual learner with Learner Profiles Service, Context Management and Delivering Service, Course Management Service, and other type of services[3]. In the future, all SCORM-compliant LMS platform can download this course for healthcare CDA teaching.

\section{CONCLUSION AND FUTURE EXPECTATION}

This study uses the example document in the CDA specification as e-learning teaching material, 


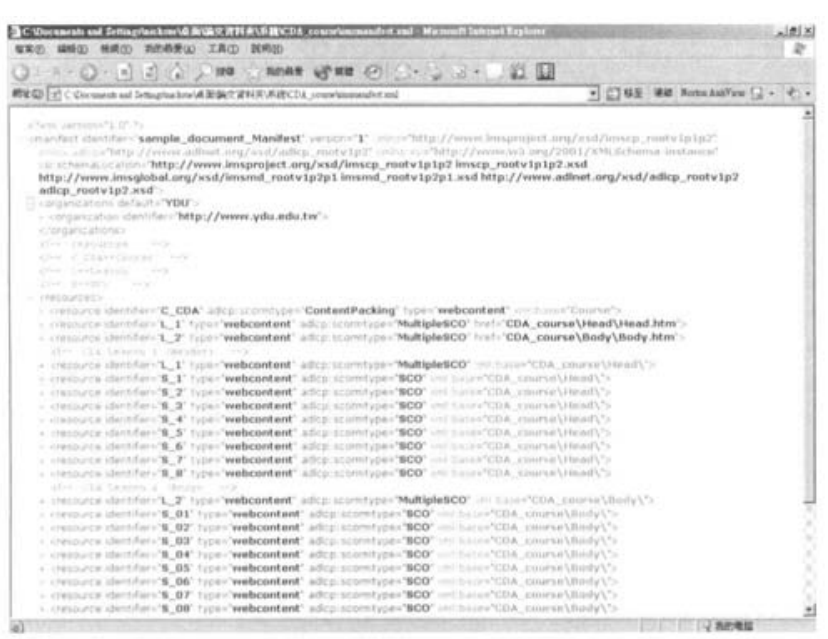

Fig 5.5.1 • imsmanifest.xml program screenshot

which is SCORM-compliant. It makes the users easier to learn HL7/CDA on the web. The finished results provide the following conveniences:

1. Provide teaching material tools for the CDA case study.

2. Assist the hospital to implement clinical document in CDA formats.

3. Make use of the reorganize able characteristic of the teaching materials, the users (teachers, physicians, or students) can freely choose, reorganize or edit content on CDA examples, as teaching materials for the classes or reference bases for the patient record implementation of the CDA document.

4. The users can directly edit the content of a CDA document and export it to become standard CDA document. Without reprogramming and understanding of CDA document architecture, the users can compile a CDA document.

Furthermore, this teaching material cuts CDA example document in details and compiles individual Metadata file. Other SCORM-compliant LMS platform can share and use this teaching material. It fully achieves the spirit of SCORM, i.e. Reusability, Accessibility, Durability, Interoperability, Adaptability, Affordability and Manageability. In the future study, we shall attempt to produce a domestic patient record in CDA document and make it comply with SCORM standard to become a future domestic reference model course for CDA patient record. On the other hand, after domestic HL7 skills mature, this result can be subsequently used in HL7 standard implementation for CDA teaching material study. Base on this result to produce a HL7-compliant CDA clinical document for teaching or clinical application.

\section{ACKNOWLEDGE}

This project uses project platform in National Science Council "2003 e-learning Country Science and Technology Plan -Development E-Learning Center for Medical and Health Education in University Hospital" (NSC 92-2524-S-002-002) project, subproject -"An Open Source Platform Development for University Hospital", supporting SCORM standard, becoming online LMS system learning interface tool.

\section{REFERENCE}

1. Rosenberg (1992), "e-learning-new chance under new challenge" in Chinese, Software Liberty Association of Taiwan, from http://www.slat.org/communique/200203

2. Hsu WJ, "e-learning standards and SCORM development" in Chinese, The Conference of Webbased Teaching and Library Information Application from http://www.lis.nccu.edu.tw/seminar/elearn/ elearnmain $2 . \mathrm{htm}$

3. Huang RH (1992), "The Current and Future Status of e-learning Platform" in Chinese, Computer Science Department, Chung Cheng University, from http://www.im.nhit.edu.tw/titbits/data/0430/数位學 習平台現況與末来.ppt

4. Lin YC (1993), "A System Integration Interface of HL7/CDA based Electronic Patient Record" in Chinese, Electrical Engineering, National Taiwan University, Master Thesis.

5. ADL (2002), SCORM Version 1.2 Content Packaging Application Profiles Examples, from http://www.adlnet.org/index.cfm? fuseaction=SCOR Down\&listing $=$ Examples

6. HL7 (2001), HL7 Version 2.4, from http://www.hl7.org/

7. Clinical Document Architecture Framework Release 2.0, DRAFT 1.05 May 21. 2002 from http://www.miforum.net/distillate/HL7/CDA_Frame work.1.05.5_21_02.doc 